\title{
PREPARO DA para-CLOROANILINA: UM EXPERIMENTO SIMPLES, RÁPIDO E BARATO
}

\author{
Renato Saldanha Bastos*, Andréa Sousa da Cunha, Lucyane Costa da Silva, Carina Cantelle Pacheco de Oliveira, \\ Cláudia M. Rezende e Angelo C. Pinto
}

Departamento de Química Orgânica, Instituto de Química, Universidade Federal do Rio de Janeiro, 21945-970

Rio de Janeiro - RJ, Brasil

Recebido em 21/11/06; aceito em 21/6/07; publicado na web em 19/12/07

\begin{abstract}
PREPARATION OF para-CHLOROANILINE: A SIMPLE, FAST AND INEXPENSIVE EXPERIMENT. Experiments simple, short and efficient for experimental disciplines in undergraduate courses in Chemistry are an excellent opportunity for students to consolidate the learning of theoretical concepts in classical chemical transformations. The use of a safe reagent, of low cost and easy access is the motivation for this communication, that describes the use of trichloroisocyanuric acid - a chlorinating agent used in the treatment of swimming pool water - for the chlorination of acetanilide, an intermediate in the preparation of para-chloroaniline.
\end{abstract}

Keywords: chlorination; para-chloroaniline; trichloroisocyanuric acid.

\section{INTRODUÇÃO}

Nos últimos anos é cada vez maior, nos cursos de Química e áreas afins, a preocupação com a não agressão ao meio ambiente. Nestes cursos vem se procurando, sempre que possível, introduzir nas disciplinas experimentais práticas nas quais os estudantes manipulem reagentes químicos de baixa toxidez, baratos, que levem a bons rendimentos nas reações onde são empregados, que não envolvam o uso de solventes orgânicos, principalmente clorados, e que não gerem resíduos, ou os gerem em pequenas quantidades ${ }^{1}$.

Neste artigo propõe-se o uso do ácido tricloroisocianúrico (1) para a cloração da acetanilida.

$$
\overbrace{\mathrm{Cl}}
$$

Em revisões recentes Barros ${ }^{2}$, Cunha e colaboradores ${ }^{3}$ e Rodrigues e colaboradores ${ }^{4}$ descreveram aplicações do ácido tricloroisocianúrico - ATCI em síntese orgânica. Este reagente, largamente aplicado na desinfecção de águas de piscinas e no tratamento de águas em geral, conhecido comercialmente como Simclosene, Genclor, Cloreal ou ACL- $85^{3}$, é barato e tem se mostrado um agente eficaz de cloração de núcleos aromáticos ${ }^{5,6}$. Neste trabalho descreve-se a preparação de para-cloroanilina a partir de anilina, usando o ácido tricloroisocianúrico como agente halogenante, em condições brandas. Este reagente, por ser sólido, de baixo custo e de fácil manuseio, tem diversas vantagens sobre outros agentes de halogenação, principalmente o cloro, devido à toxicidade deste gás e sobre outros agentes de cloração como a $\mathrm{N}$ clorosuccinimida e $\mathrm{N}$-clorosacarina ${ }^{7}$, por estes serem reagentes importados e mais caros.

A cloração de compostos orgânicos utilizando cloro em fase gasosa é bastante trabalhosa e perigosa. Como descrito por $\mathrm{Vogel}^{8}$, é necessário para a produção do referido gás um balão contendo permanganato de potássio sob aquecimento onde se goteja ácido clorídrico concentrado. O gás cloro é então produzido e, em segui-

*e-mail: bastosrs@ufrj.br da, passa por uma seqüência de três "traps" contendo água (no primeiro) e ácido sulfúrico concentrado (nos dois últimos). O terceiro "trap" tem função de aliviar a pressão produzida no interior do sistema ("trap" de segurança). O gás é sempre produzido em excesso, devido a sua baixa reatividade. Por último, há a constante preocupação com a toxidez do gás cloro produzido.

\section{PARTE EXPERIMENTAL}

\section{Materiais e métodos}

Os espectros de RMN de ${ }^{1} \mathrm{H}$ e RMN de ${ }^{13} \mathrm{C}$ foram obtidos a 200 e $50 \mathrm{MHz}$, respectivamente, em aparelho Bruker DRX-200, utilizando o tetrametilsilano (TMS) ou o núcleo do hidrogênio residual do clorofórmio deuterado $\left(\mathrm{CDCl}_{3}\right)$ e do dimetilsulfóxido deuterado (DMSO-d $)_{6}$ como referencial interno.

A análise por CG-EM foi realizada em um instrumento Agilent 5973 (Palo Alto, EUA), com impacto de elétrons a $70 \mathrm{eV}$, coluna DB-5 (30 m x 0,25 mm x 1,0 $\mu$ m; Hewlett Packard Co., PA, EUA), modo de injeção com divisão de fluxo de 1:20, gás carreador hélio, pressão constante de $4,5 \mathrm{psi}$, temperatura do injetor $270{ }^{\circ} \mathrm{C}$. Programação de temperatura: temperatura inicial $100{ }^{\circ} \mathrm{C}$ durante $3 \mathrm{~min}$, rampa de aquecimento de $20^{\circ} \mathrm{C} / \mathrm{min}$ até $270{ }^{\circ} \mathrm{C}$, isoterma de $2 \mathrm{~min}$.

Foi injetado $1 \mu \mathrm{L}$ dos produtos solubilizados em diclorometano.

Os espectros na região do infravermelho (IV) foram obtidos em espectrofotômetro Nicolet-Magna 760 utilizando pastilhas de brometo de potássio. Os valores para as absorções são referidos em números de ondas, utilizando como unidade o centímetro recíproco $\left(\mathrm{cm}^{-1}\right)$.

Os pontos de fusão não foram corrigidos e foram obtidos em aparelho MEL-TEMP II.

\section{Obtenção da acetanilida}

A acetanilida 3 foi obtida, em bom rendimento (84\%), a partir da acetilação da anilina $\mathbf{2}$ e foi purificada por recristalização em água. A preparação da acetanilida é a primeira aula da disciplina Experimental de Química Orgânica II do Curso Noturno de Licenciatura do Instituto de Química da UFRJ ${ }^{9,10}$ (Esquema 1).

A acetanilida ${ }^{11} \mathbf{3}$ foi caracterizada pelo ponto de fusão de $113{ }^{\circ} \mathrm{C}$ (literatura $113-115^{\circ} \mathrm{C}$ ) e pelas absorções no infravermelho. 


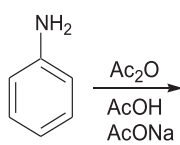

2<smiles>CC(C)Nc1ccccc1</smiles>

3

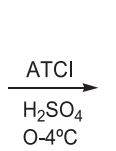

$\mathrm{O}-4^{\circ} \mathrm{C}$<smiles>CNc1ccc(Cl)cc1</smiles>
i) $70 \%(\mathrm{p} / \mathrm{p}) \mathrm{H}_{2} \mathrm{SO}_{4}$,
REFLUXO ii) $20 \% \mathrm{NaOH}$<smiles>Nc1ccc(Cl)cc1</smiles>

Esquema 1

\section{Cloração da acetanilida}

A uma suspensão de acetanilida $3(0,68 \mathrm{~g}, 5 \mathrm{mmol})$ em $\mathrm{H}_{2} \mathrm{SO}_{4}$ conc. $(6,0 \mathrm{~mL})$ em um Becker de $25 \mathrm{~mL}$, mantida sob agitação magnética em banho de gelo, entre 0 e $4{ }^{\circ} \mathrm{C}$, adicionou-se, em pequenas porções, o ácido tricloroisocianúrico 1 (0,52 g, 2,25 mmol). Após 15 min, verteu-se a solução da reação para um Becker contendo aproximadamente $50 \mathrm{~mL}$ de gelo (Esquema 1). O precipitado formado foi filtrado a vácuo em funil de Büchner e recristalizado em uma mistura de água/etanol (70:30). A para-cloroacetanilida ${ }^{12} \mathbf{4}$ foi obtida, após recristalização, em $56 \%$ de rendimento ${ }^{13}$ e caracterizada por ponto de fusão: $178{ }^{\circ} \mathrm{C}$ (literatura $178-179{ }^{\circ} \mathrm{C}$ ) e por dados espectroscópicos de IV, RMN ${ }^{1} \mathrm{H}$ e $\mathrm{RMN}{ }^{13} \mathrm{C}$.

\section{Hidrólise da para-cloroacetanilida}

Em um balão de fundo redondo conectado a um condensador de refluxo foram adicionados: 1,76 $\mathrm{g}$ de para-cloroacetanilida $4 \mathrm{e}$ $10 \mathrm{~mL}$ de solução a $70 \%(\mathrm{p} / \mathrm{p})$ de $\mathrm{H}_{2} \mathrm{SO}_{4}$. A mistura foi refluxada durante $40 \mathrm{~min}$ e vertida, ainda quente, sobre $50 \mathrm{~mL}$ de água destilada gelada, adicionando-se, em seguida, $40 \mathrm{~mL}$ de solução aquosa $20 \%$ de $\mathrm{NaOH}$ (ou quantidade suficiente para a formação de precipitado branco). $\mathrm{O}$ precipitado branco formado foi filtrado a vácuo em funil de Büchner e lavado com água gelada (Esquema 1). A para-cloroanilina ${ }^{14} 5$ foi obtida em $56 \%$ de rendimento e caracterizada pelo ponto de fusão $72{ }^{\circ} \mathrm{C}$ (literatura $72,5^{\circ} \mathrm{C}$ ) e pelos dados de IV, RMN ${ }^{1} \mathrm{H}$ e $\mathrm{RMN}{ }^{13} \mathrm{C}$.

\section{RESULTADOS E DISCUSSÃO}

A halogenação eletrofílica de compostos aromáticos é uma reação bastante estudada em química orgânica. Ela ocorre através de uma substituição eletrofílica, com o ataque ao eletrófilo pelos elétrons da ligação pi do anel aromático. A etapa lenta da reação é a formação do intermediário catiônico de Wheland que, em seguida, perde um próton, para restaurar a aromaticidade. A entrada do eletrófilo é governada pela natureza do substituinte que estiver ligado ao anel aromático.

No caso da cloração da acetanilida a substituição pode ocorrer nas posições orto e para, devido ao aumento de densidade eletrônica do anel conferida pelo grupo ativador NHAc. Observou-se por cromatografia gasosa que apenas o produto monoclorado na posição para do anel aromático foi obtido a partir do precipitado formado, após a reação ser vertida sobre gelo. Entretanto, depois de se neutralizar a solução ácida com solução aquosa de $\mathrm{NaOH}$ e proceder-se à extração da fase aquosa com acetato de etila, constatouse por CG-EM a presença do produto monoclorado na posição orto(traços) e do produto diclorado, além da para-cloroacetanilida.

Quando a fase aquosa ácida obtida após a lavagem com água é concentrada, por aquecimento, formam-se no fundo do becker cristais finos em forma de agulhas de coloração avermelhada. O espectro de infravermelho mostrou que estes são cristais de ácido isocianúrico 6.

É possível aumentar o rendimento da para-cloroacetanilida 4 se a solução ácida da reação de cloração for neutralizada com hidróxido de sódio e, em seguida, for extraída com acetato de etila. É necessá-<smiles>O=c1[nH]c(=O)[nH]c(=O)[nH]1</smiles>

rio, entretanto, recristalizar duas vezes o sólido formado com mistura de água/etanol (70:30), para remoção da orto-cloroacetanilida e 2,4-dicloroacetanilida. Com este procedimento chega-se a um rendimento total de $62 \%$ de para-cloroacetanilida pura.

\section{CONCLUSÃO}

Este trabalho mostra uma nova possibilidade de uso do ácido tricloroisocianúrico, um reagente barato e de manipulação fácil. Este pode ser usado, com sucesso, para a cloração de sistemas aromáticos ativados em aulas experimentais de cursos de Química e Farmácia.

Por se tratar de uma reação muito rápida, permite que o estudante faça a síntese, recristalize e hidrolise para-cloroacetanilida a para-cloroanilina em uma mesma aula.

A cloração da acetanilida com o ATCI ou com o produto comercial Genclor tem inúmeras vantagens sobre a N-clorosuccinimida e $\mathrm{N}$-clorosacarina. Além de ser um reagente de baixíssimo preço $(\mathrm{R} \$ 6,00$ - $200 \mathrm{~g})$ é mais seletivo para a obtenção do produto clorado na posição para e, depois de neutralizada, a solução salina poderá ser descartada sem maiores preocupações.

\section{AGRADECIMENTOS}

Ao PRONEX, CNPq, à FAPERJ, CAPES e FUJB pelo apoio financeiro e bolsas concedidas, e às Centrais Analíticas (IQ/UFRJ).

\section{REFERÊNCIAS}

1. Anastas, P. T.; Warner, J. C.; Green Chemistry: Theory and Practice, Oxford University Press: Great Britain, 2000.

2. Barros, J. C.; Synlett 2005, 13, 2115.

3. Cunha, A. C.; Paixão, F. M.; Souza, M. C. B. V.; Ferreira. V. F.; Quim. Nova 2006, 29, 520 .

4. Rodrigues, R. C.; Barros, I. M. A.; Lima, E. L. S.; Tetrahedron Lett. 2005, 46,5945 .

5. Ribeiro, N. M.; Pinto, A. C.; Silva, B. V.; Violante, F. A.; Rezende, C. M.; Org. Prep. Proced. Int. 2005, 37, 265.

6. Mendonça, G. F.; Magalhães, R. R.; Mattos, M. C. S.; Esteves, P. M.; J. Braz. Chem. Soc. 2005, 16, 695.

7. Souza, S. P. L.; Silva, J. F. M.; Mattos, M. C. S.; J. Braz. Chem. Soc. 2003, 14,832 .

8. Vogel, A. I.; Vogel's Textbook of Pratical Organic Chemistry, $5^{\text {th }}$ ed./rev. by Furniss B.S.; et al., John Wiley \& Sons, Inc:, New York, 1989.

9. Mano, E. B.; Seabra, A. P.; Práticas de Química Orgânica, $3^{\mathrm{a}}$ ed., Ed. Edgard Blücher Ltda: São Paulo, 1987.

10. Vogel, A. I.; Química Orgânica. Análise Orgânica Qualitativa, $2^{\mathrm{a}} \mathrm{ed}$., Ao Livro Técnico S. A.: Rio de Janeiro, 1982.

11. Dados espectroscópicos da acetanilida 3: IV $\left(\mathrm{KBr} / \mathrm{cm}^{-1}\right) v_{\text {máx }}: 3295,1665$, $1598,1435,1322,758,694$

12. Dados espectroscópicos da para-cloroacetanilida 4: $\mathrm{IV}\left(\mathrm{KBr} / \mathrm{cm}^{-1}\right) \mathrm{v}_{\text {máx }}$ : $3305,1665,1608,1540,1490,830 . \mathrm{RMN}^{1} \mathrm{H}\left(200 \mathrm{MHz}, \mathrm{CDCl}_{3}\right) \delta(\mathrm{ppm})$ : $(\mathrm{s}, 1,89,3 \mathrm{H}),(\mathrm{d}, 6,96-7,00,2 \mathrm{H}),(\mathrm{d}, 7,31-7,36,2 \mathrm{H}),(\mathrm{s}, 9,31,1 \mathrm{H}) . \mathrm{RMN}$ ${ }^{13} \mathrm{C}\left(50 \mathrm{MHz} \mathrm{CDCl}_{3}\right) \delta$ (ppm): 23,7; 120,5; 127,5; 128,0; 137,3; 168,6.

13. Vale ressaltar que para se conseguir o rendimento esperado, deve-se, na etapa de recristalização, concentrar a solução até observar a turvação da mesma, e só então desligar o aquecimento. Após seu resfriamento proceder à filtração.

14. Dados espectroscópicos da para-cloroanilina 5: IV $\left(\mathrm{KBr} / \mathrm{cm}^{-1}\right) v_{\text {máx }}: 3473$, $3382,1616,1493,1088,820,640 . \mathrm{RMN}^{1} \mathrm{H}\left(200 \mathrm{MHz}, \mathrm{CDCl}_{3}\right) \delta(\mathrm{ppm})$ : $(\mathrm{s}, 3,57,2 \mathrm{H}),(\mathrm{m}, 6,57,2 \mathrm{H}),(\mathrm{m}, 7,07,2 \mathrm{H}) . \mathrm{RMN}{ }^{13} \mathrm{C}\left(50 \mathrm{MHz}, \mathrm{CDCl}_{3}\right) \delta$ (ppm): 116,2; 122,9; 129,1; 145,1. 